\title{
Concepções de família e práticas de intervenção: uma contribuição antropológica
}

\section{Family conceptions and practices of intervention: an anthropological contribution}

Claudia Fonseca

Professora Doutora do Programa Pós Graduação em Antropologia Social-UFRGS

E-mail: claudiaf2®uol.com.br

\section{Resumo}

Falar sobre a família como foco de intervenção exige aprofundar a discussão sobre o que é uma família e como ela pode servir ou não de recurso em programas de intervenção; exige também problematizar um elemento básico do processo de intervenção: a comunicação entre técnicos que atuam na intervenção e a população-alvo. Assim, neste trabalho, sugere-se, num primeiro momento, algumas pistas analíticas que podem ajudar o técnico a perceber dinâmicas familiares em grupos populares do Brasil. Descobrimos assim que, da perspectiva espacial, redes de parentesco se estendem além do grupo consangüíneo e da unidade doméstica para esferas mais amplas. Da perspectiva temporal, as pessoas se inserem em uma sucessão de gerações, possibilitando projeções para o futuro ou resgates de elementos do passado. Passa-se então a considerar a contribuição específica de uma teoria da prática e as implicações metodológicas de uma análise centrada em "modos de vida", arraigados numa situação de classe. Finalmente, comenta-se o olhar reflexivo - um elemento fundamental do processo dialógico que permite a escuta do outro em qualquer situação de intervenção. Propõe-se com essa abordagem descolonizar o olhar do técnico, propiciando uma interação dialógica capaz de reforçar, antes de reprimir, recursos tradicionais na situação em que se pretende intervir.

Palavras-chave: Família; Parentesco; Ciclo Familiar; Intervenção; Metodologia de pesquisa; Modo de vida. 


\section{Abstract}

To speak of the famliy as focus of intervention not only demands a probing discussion about what constitutes a family and how this social group may or may not be an important ressource in intervention programs, it also demands a close look at a basic element of the intervention process: the communication between intervening professionals and the target population. Thus, in this article, we first consider certain analytical leads that might help professionals perceive family dynamics in Brazilian working-class groups. We discover that, from a spatial perspective, family networks reach beyond the consanguineal or household units to much wider spheres; from a temporal perspective, individuals are embedded in the play of successive generations, allowing for a projection of relations into the future or salvaging of elements from the past. We then consider the specific contribution of an approach involving practice theory, and the methodological implications of centering the analysis on "lifestyles", involving class-bound specificities. Finally, we outline properties of the "reflexive gaze" - a fundamental element in the dialogical process that permits one to hear what others are saying. We propose, with this approach, to contribute toward the "decolonization" of intervention projects, encountering manners to reinforce rather than repress traditional social and community ressources.

Key Words: Family; Kinship; Family Cycles; Intervetion; Research Methodology; Lifestyles.
Falar sobre família como foco de intervenção exige aprofundar a discussão sobre o que é uma família e como ela pode servir ou não de recurso em programas de intervenção; exige também problematizar um elemento básico do processo de intervenção: a comunicação entre agentes de intervenção e a população-alvo. Assim, neste trabalho, sugiro, num primeiro momento, algumas pistas analíticas que podem ajudar a perceber dinâmicas familiares em grupos populares. Passo então a enfatizar a importância de uma teoria da prática, e as implicações metodológicas de uma análise centrada em "modos de vida". Finalmente, comento o olhar reflexivo - um elemento fundamental do processo dialógico que permite a escuta do outro em qualquer situação de intervenção ${ }^{1}$.

\section{Família versus Indivíduo}

Elsen e Althoff (2004) ${ }^{2}$ colocam perguntas desafiadoras para o trabalhador de saúde: qual a distinção entre as necessidades da família como coletividade e as necessidades dos indivíduos separados que compõem essa família? Será que não há elementos incompatíveis entre a saúde da família e a saúde dos membros individuais?

Para responder a tais questões, temos que primeiro saber como conceituar família. Recorremos à reflexão do antropólogo brasileiro Luis Fernando Duarte (1994), para iniciar o assunto. Segundo ele, o valor "família" tem grande peso em todas as camadas da população brasileira. No entanto, significa coisas diferentes dependendo da categoria social. Enquanto, entre pessoas da elite, prevalece a família como linhagem (pessoas orgulhosas de seu patrimônio), que mantêm entre elas um espírito corporativista, as camadas médias abraçam em espírito e em prática a família nuclear, identificada com a modernidade. Para os grupos populares o conceito de família está ancorada nas atividades domésticas do dia-a-dia e nas redes de ajuda mútua.

1 Não há oportunidade, no curto espaço deste artigo, de descrever a vasta literatura que existe na área de antropologia do corpo e da saúde. No entanto, coerente com minha preocupação metodológica, cabe citar uma obra de metodologia etnográfica voltada para trabalhadores de saúde: Pesquisa qualitativa em saúde, de Ceres Victora et al. (2002).

2 ELSEN, I.; ALTHOFF, C. R. (Org.). Saúde da família? Multiplicar ou clarear conceitos? 2004. Trabalho apresentado no $56^{\circ}$ Congresso de Enfermagem, Gramado, 2004 
Essa maneira de tentar associar certo modo de vida a determinada configuração familiar - agora num contexto diferente - pode ser observada na pesquisa da antropóloga norte-americana Rayna Rapp (1992), na qual ela faz uma comparação de famílias brancas de camadas médias e famílias negras pobres dos Estados Unidos. Conforme essa pesquisadora, na ideologia altamente individualista das classes médias americanas, os parentes são assimilados à categoria de “amigos”, de forma a poder eliminar os que não respeitam as regras da amizade. Dessa forma, os indivíduos com muitos problemas são afastados da convivência familiar, tal como uma perna gangrenada é cortada para manter a saúde do corpo. O filho perdulário é deserdado, o sobrinho doente é esquecido, a avó caduca é deixada numa instituição - tudo em nome do bom desenvolvimento e ascensão da família nuclear. A noção de família é reduzida a unidade linear - de pais para filhos \% para evitar os riscos de dissipar recursos. Tudo é investido nos filhos, na sua educação, na sua carreira profissional.

Por outro lado, as famílias negras pobres, que vivem em condições de grande precariedade econômica, só conseguem sobreviver porque criam extensas redes de ajuda mútua. Tornam-se membros pertinentes dessa rede familiar não somente pais, mas irmãos, tios, primos, ex-sogros, compadres e até amigos. Assim, é comum encontrar na casa de uma mulher, além dela e dos filhos, uma diversidade de indivíduos: um primo, recém chegado do interior para procurar trabalho, dormindo no sofá, um sobrinho, cujos pais acabam de se separar, comendo na mesa da cozinha, etc. A dona de casa vai ajudar essas pessoas, por carinho, mas sobretudo porque eles a ajudaram ou a ajudarão. A família aqui se estende horizontalmente, numa partilha constante, nem sempre pacífica, de recursos.

É possível Quando li essa descrição, não pude deixar de fazer uma aproximação aproximação entre as famílias negras norte-americanas descritas por Rapp e famílias de grupos populares brasileiros, encontradas durante minhas pesquisas de campo (Fonseca, 2004). Lá também os poucos recursos de qualquer núcleo familiar parecem ser constantemente drenados para pessoas necessitadas da família extensa. No estudo realizado em 2004 lembro-me de Vanilda, uma amiga que ganha a vida como empregada doméstica, explicando por que nunca compra eletrodomésticos a vista, mesmo sabendo que a mercadoria seria muito mais barata assim: "Claudia", ela me explica, "Pense bem. Se eu tivesse dinheiro na poupança, como que ia resistir? Sempre tem, em algum lugar da família, um nenê que está com pneumonia e precisa de remédio, ou um primo que se meteu em encrenca e vai ir preso se a gente não achá dinheiro para pagar o advogado. Sempre tem alguma coisa urgente acontecendo e, nesse caso, como que eu ia guardar o dinheiro para mim? Se eu não comprasse a máquina a prazo, aí sim, não ia nunca ter dinheiro para comprar!"

Quando Vanilda diz que sempre tem um nenê na família que está doente, ela se refere à família no sentido mais amplo, que inclui um leque quase infindável de primos, ex-cunhadas, sobrinhos e outros. Além de criar suas cinco filhas praticamente sozinha, pois enviuvou muito cedo, já abrigou na sua casa uma longa lista de parentes. Apesar de reconhecer que essa generosidade limita sua capacidade de investir no futuro de suas próprias filhas, não consegue imaginar outra maneira de agir. Seu lema é explicitado no provérbio que ela mesma cita: "Onde come um Português, come dois, três” - uma noção que parece muita próxima a filosofia das famílias descritas por Rapp. Segundo Vanilda, quando esteve "na pior" - viúva, bóia-fria e analfabeta, com menos de 30 anos e quatro crianças para criar -, ela recebeu ajuda de muitas pessoas a quem, hoje, ela ajuda.

Sua história sublinha o ponto que quero reter aqui. Quando falamos de um possível desencontro entre a saúde individual e a saúde da família, de que família estamos falando? As camadas médias, pensando no bem do núcleo pai e filhos, tenderiam a cortar os elementos estranhos e potencialmente perturbadores. Reduzindo “a família” ao número mínimo de indivíduos, há muito mais chance de fazer coincidir “a saúde da família" com a "saúde dos indivíduos". Nas famílias pobres, por outro lado, parece que certas pessoas acabam sacrificando seus projetos individuais ou os de seu núcleo familiar para salvar indivíduos problemáticos da rede extensa de parentes. Assim, a relação indivíduo - família não pode ser pensada da mesma forma em todo lugar, pois a própria noção de família varia conforme a categoria social com qual estamos lidando. 


\section{Elementos Analíticos para Pensar a Família: além da unidade doméstica}

Qual ao arsenal teórico que pode nos ajudar a dar conta dessa variedade de noções de família, Talvez devamos começar fazendo uma distinção entre "família" e "unidade doméstica". Os censos do IBGE - Instituto Brasileiro de Geografia e Estatística - trabalham em geral com a unidade doméstica e, portanto, definem vida familiar a partir da moradia. Trata-se de uma visão limitada, que não leva em consideração justamente a parte mais dinâmica das relações familiares - e que em geral extrapola em muito "a casa".

Muitos dos moradores de bairros pobres pensam não em termos de "casa", mas sim em termos de "pátio". Em um terreno, por menor que seja, sempre tem lugar para construir mais uma "puxada", isto é, uma peça ou uma meia-água, para receber um amigo ou parente. A primeira moradia da maioria de jovens casais é uma peça construída no quintal dos pais ou sogros. Com filhos casando e descasando, pessoas mudando atrás de um novo emprego, ou simplesmente com a incorporação de algum inquilino, a composição do pátio muda. Mas, seja qual for a relação formal, é comum que haja uma troca intensiva entre essas "casinhas" para a realização de tarefas domésticas. Quando uma mulher trabalha fora, por exemplo, as outras do pátio tendem a suprir sua parte na organização doméstica - fornecendo almoço quente para os sobrinhos, e supervisionando as brincadeiras dos filhos pequenos. A parte mais visível desse processo é o cuidar de crianças - o que leva a uma intensa "circulação de crianças” e a situação não é tão incomum de um indivíduo ser criado por, o que ele próprio considera, suas duas ou três “mães" (Fonseca 2002). É também possível encontrar diversos núcleos familiares repartindo comida. Até os mais pobres, que não têm geladeira, são capazes de chamar os outros moradores do pátio ou do beco para comerem juntos quando recebem doação de carne ou outra comida que estraga (Jardim, 1998).

Nesses casos, é difícil definir exatamente quais são os limites da própria unidade doméstica.

Em suma, para qualquer intervenção, especialmente em grupos populares, seria fundamental verificar como as atividades do dia-a-dia envolvem uma rede que se estende no espaço para outras casas e até mesmo para outros bairros. Traçando as linhas de ajuda mútua, podemos melhor refletir sobre o que é, nessa instância, a "família" pertinente.

\section{A Dimensão Temporal da Família}

Vimos que a rede familiar, unidade relevante para qualquer trabalho de intervenção, se estende no espaço além das quatro paredes de uma casa. Seria importante agora lembrar que as relações familiares, sendo relativamente duradouras, seguem uma lógica que se estende no tempo através de diversas gerações e através de muitos anos, isto é, as diferentes etapas de uma troca "mútua" nem sempre ocorrem no imediato. Por exemplo, um observador desavisado poderia considerar que aquela avó que assimilou no seu núcleo doméstico e arcou com as despesas dos primeiros netos está numa relação de "mão-única”, na qual ela ajuda seu filho e neto sem receber nada em troca. No entanto, devemos lembrar que esta avó está marcando seu lugar na rede familiar, reforçando através de seu dom a obrigação que seus descendentes têm de cuidar dela anos mais tarde na velhice - justamente quando ela passa a ocupar o lado mais fraco da relação familiar. Não se trata de um cálculo consciente nem de um investimento garantido, que sempre dê retorno. Entretanto, a lógica da rede extensa de família - a lógica do dom, como nos ensina Marcel Mauss (1974) \% implica numa reciprocidade a longo prazo; uma reciprocidade que, contrariamente à lógica do contrato ou até mesmo de amizades fugazes, coloca uma fé difusa em um retorno eventual, em alguma data futura, por algum membro da rede implicada na dádiva original.

A idéia de "ciclo de vida" é subsidiária a essa discussão sobre a dimensão temporal das relações familiares. Antropólogos clássicos, como, por exemplo, Fortes (1958), definiram três fases do que consideravam um universal núcleo familiar: formação inicial (em geral, por casamento), expansão (com nascimento dos filhos), e declínio (quando os filhos adultos saem para estabelecer seus próprios núcleos, e a velha geração é deixada com "o ninho vazio"). Nas últimas décadas, pesquisadores confirmaram que a trajetória de qualquer família é bem mais complicada do que isso (Bilac, 1978; Barros, 1987). Sabemos, por 
exemplo, que, especialmente em grupos populares, as etapas do ciclo doméstico não são nítidas. Muitas vezes o nascimento de netos precede o casamento de seus pais ou a formação de um novo núcleo. Ainda mais, em época de desemprego, há uma tendência crescente em todas as classes de filhos adultos voltarem para a casa dos pais em momentos difíceis, seguindo um divórcio ou a perda de emprego (Peixoto, 2004). Assim, hoje em dia, o ciclo familiar baseado na nuclearização das famílias não é nada evidente.

No entanto, mesmo que não exista um só padrão, é inegável que a maioria de núcleos domésticos "evoluem" com o tempo. Pais de 16 anos não têm as mesmas opções, não se comportam da mesma forma, não têm as mesmas expectativas que pais de 30 ou 60 anos. Aqui, posso citar o exemplo de Dona Maria, que finda a adolescência, sem emprego ou companheiro fixo, não encontrava outra solução para o bem-estar de seus filhos, senão a colocação em diferentes famílias de criação. Dez anos mais tarde, ela se estabeleceu com um "homem trabalhador" 3 e, além de fazer uma nova família com ele, procurou trazer para seu convívio os filhos mais velhos. No domingo em a conheci, Dona Maria estava reunida no seu quintal com seis dos seus sete filhos, a maioria agora adulta, fazendo um churrasco.

A trajetória de Dona Maria e seus filhos não é incomum. Se seu núcleo familiar fosse observado durante a primeira etapa de sua trajetória, apareceria uma dispersão aparentemente caótica dos membros. Seria exemplo por excelência da "família desestruturada”. Em outro momento, mais avançado, do ciclo doméstico, observamos Dona Maria confortavelmente instalada com seu companheiro em casa própria, fornecendo um lugar de encontro, e, mais, uma âncora de identidade para os diferentes indivíduos de uma família ostensivamente "unida".

O profissional de saúde, realisticamente, tem apenas uma entrada para as famílias com as quais trabalha - uma entrada que comporta um lugar apenas (em geral, a casa) e um tempo (a atualidade). Entretanto, para interagir com os membros dessas famílias, que são envolvidos em relações que vão além do "aqui e agora", é necessário que fiquer atento às dinâmicas que extrapolam seu limitado campo de observação, acionando o arsenal teórico adequado.

Devemos lembrar que não há receita para definir os membros relevantes de uma rede familiar. Essa pode ou não incluir consangüíneos (ascendentes, descendentes, colaterais etc.), parentes por casamento (sogros, cunhados, concunhados, padrastos, enteados etc.), padrinhos e compadres (não devemos esquecer que existem padrinhos em casa, de igreja, na família de santo, etc.), e simplesmente amigos que, depois de ter compartilhado uma experiência particularmente intensa, acabam se sentindo membro da família.

Procurando uma definição operacional da vida familiar que dê conta desse vasto leque de possibilidades, preferimos falar de dinâmicas e relações familiares, antes do que de um modelo ou unidade familiar. Assim, definimos o laço familiar como uma relação marcada pela identificação estreita e duradoura entre determinadas pessoas que reconhecem entre elas certos direitos e obrigações mútuos. Essa identificação pode ter origem em fatos alheios à vontade da pessoa (laços biológicos, territoriais), em alianças conscientes e desejadas (casamento, compadrio, adoção) ou em atividades realizadas em comum (compartilhar o cuidado de uma criança ou de um ancião, por exemplo).

\section{Repercussões metodológicas do recorte "modo de vida": a teoria da prática}

Gostaria, agora, de adentrar uma outra faceta dessa discussão, inspirada no trabalho de Dytz (2004) ${ }^{4}$, sobre modo de vida - em particular, sobre as implicações metodológicas de uma abordagem centrada na questão de modo de vida.

Desde os anos 1970, Pierre Bourdieu (1972), entre outros, nos previne contra abordagens analíticas focadas exclusivamente nos ideais - as representações normativas de uma sociedade. Na linha de investigação que ele inspirou - "a teoria da prática" -, pesquisadores insistem na relação dialética entre práticas e valores. Valores, nessa ótica, não seriam considera-

\footnotetext{
3 Para mais informação sobre a importância desse valor nas relações de gênero de grupos populares, ver Sarti (1996).

4 DYTZ, J. L. 0 modo de vida da família e a saúde infantil. 2004. Trabalho apresentado no 56º Congresso de Enfermagem, Gramado, 2004
} 
dos estanques, parados no tempo, nem algo externo que pudesse ser imposto a um grupo. Pelo contrário, valores seriam constantemente reconstruídos - modificados ou reatualizados, investidos de novo significado -, por meio da prática de atores sociais agindo dentro de um contexto específico.

0 problema é que muitas pesquisas são presas a uma visão jurídica da realidade. É como se bastasse constatar a lei, repertoriar as normas hegemônicas, e medir a realidade contra esse parâmetro. Seguindo esse enfoque "legalista", veríamos, no estudo da família, que certas pessoas se aproximam mais do ideal da família conjugal nuclear, e outras menos, e muito pouco além disso. É assim que, durante as primeiras gerações de estudo da família, os pobres eram vistos como "a massa amorfa" dos "sem-família"5. 0 modelo, antes de nos ajudar, agiria como camisa de força, impondo-nos um tipo de viseira que impedisse uma melhor visão da realidade. Não veríamos, por exemplo, a atitude criativa dos atores - como alguns deles burlam ou brincam com a norma oficial, como criam normas alternativas, enfim, como, por meio de suas práticas cotidianas, estão constantemente renegociando e transformando valores.

Tal é a força da matriz jurídica em nossa socialização que, muitas vezes, é difícil para profissionais fazerem uma associação entre suas próprias práticas familiares e as teorias (da família). Convidada por um grupo de conselheiros tutelares para falar sobre família, Tive dificuldade sobre por onde começar. Queria a todo custo evitar soluções fáceis. Não queria apresentar modelos prontos - como se a realidade pudesse ser encaixada em algumas regras preestabelecidas. Só baixou a angústia quando me dei conta que a apresentação antropológica de família só faria sentido se começássemos a partir das famílias dos próprios conselheiros. Assim, pedi para eles sentarem em pequenos grupos e elaborar a árvore genealógica de algum voluntário entre eles.

0 resultado, para mim pelo menos, foi muito revelador. Em primeiro lugar, as pessoas descobriram que tinham muitas dúvidas sobre como definir a família. Já que o exercício era ligado ao seu desempenho enquanto conselheiros e a eventual necessidade de in- tervir em certas famílias de seus bairros; combinamos que eles deviam incluir no esquema genealógico do voluntário todos os parentes que tivessem alguma relevância nas atividades do dia-a-dia ou nas cerimônias rituais de família (batismo, aniversário, formatura, etc.). A partir disso, os conselheiros começaram a se dar conta de que a realidade de suas famílias não cabia facilmente naqueles diagramas lineares. Lembro-me do caso de "Seu" Adão, um senhor com cerca de 50 anos, que confessou timidamente que, conforme sua carteira de identidade, tinha pai, mas era de "mãe desconhecida". Como podia ser? Sua mãe tinha tido três companheiros - o primeiro com o qual casou legalmente, o segundo com o qual geriu "Seu” Adão, e o terceiro com quem viveu trinta anos. Foi esse terceiro quem o registrou, mas na hora do registro, omitiu o nome da mãe, pois ela ainda era casada e tinha medo que seu marido legal - e portanto pai oficial da criança - reclamasse seus direitos paternos. Para o "Seu" Adão, esse terceiro companheiro da mãe - o pai que o criou - era seu verdadeiro pai, mas o diagrama que tentava esboçar no papel parecia colocar em relevo apenas os laços de sangue e uniões oficiais.

Jailton, objeto voluntário de estudo de outro grupo, queria saber se deveria incluir ou não em seu diagrama a ex-esposa e o novo marido dela. Ele tinha se juntado três vezes, encontrando-se no momento da realização do estudo solteiro. Vivia, no entanto, no pátio de sua mãe, "a seis metros" da casa de sua segunda mulher. Esta era a mãe de seu único filho e continuou a dividir com a mãe de Jailton os cuidados cotidianos da criança. Esta avó jurava que ela só reconhecia uma nora - a mãe de seu neto - e, morando lado a lado, no pátio, continuaram a tomar chimarrão juntas toda a tarde. De certa forma, quisesse Jailton ou não, sua exesposa permanecia como membro relevante de sua família.

Aqui, não há espaço para repertoriar todos os riquíssimos resultados desse exercício com os conselheiros, cujas histórias, sem dúvida não são tão diferentes das de muitos outros agentes de intervenção. Para mim foi fascinante. Havia de tudo: árvores genealógicas viradas de pernas para o ar que incluíam a empregada doméstica e a professora de colégio; clãs

5 Para maior elaboração dessa crítica, ver Corrêa (1993). 
italianos com repetidos casamentos entre primos; pais relapsos confessos, que negavam o laço de parentesco e se recusavam a pagar a pensão alimentícia ao filho nascido de uma relação passageira (algo bastante surpreendente para um conselheiro tutelar, eleito para promover os direitos da criança) e assim adiante. Havia de tudo, de fato, menos a simples e reduzida família conjugal nuclear, tão badalada como norma hegemônica. O mais interessante foi que nenhum dos voluntários considerou sua "família desestruturada”. Assim, a partir da experiência deles, passamos a pensar como existiam - além do ideal normativo outros arranjos, outras possíveis estruturas familiares que pudessem ordenar as práticas e dar sentido à existência. Insisto que foi na observação cuidadosa das práticas e, nesse caso, de suas próprias práticas, que esses profissionais passaram a sair da "camisa de força” dos modelos jurídicos e pensar as dinâmicas sociais em toda sua criatividade.

\section{A Arte de Escutar: um processo re- flexivo}

Não é por acaso que, para introduzir as pessoas numa abordagem de prática, pedimos para elas pensarem suas próprias práticas. Afinal, essa auto-reflexão, uma maneira de virar a lente analítica para a própria cultura, para os próprios valores do observador, já é parte integrante das ciências sociais hoje, como aponta, por exemplo, Geertz (1999). Barrando essa política, é muito fácil incorrer no raciocínio evolucionista da época colonial, quando o pesquisador se considerava representante do mundo civilizado e todos os outros - os bárbaros e selvagens - eram "outros" a serem convertidos, salvos, ou simplesmente desenvolvidos, isto é, eram tudo menos pessoas a serem escutadas, parceiros em diálogo. A idéia hoje é que, para o diálogo acontecer, para romper a distância cientificista entre observador e observado, devemos saber examinar as obviedades de nossa própria cultura. Assim, também nos tornamos objetos de pesquisa (Velho, 1978).

Confesso que, até realizar o exercício didático com os conselheiros, eu, assim como eles, tinha a convicção de vir de uma família absolutamente padrão. Citava minha família - norte-americana e nuclear - como protótipo da família nuclear moderna, tudo conforme a norma hegemônica. Entretanto, quando embarquei no exercício e comecei a diagramar meus parentes relevantes, dei-me conta de certas "estranhezas". Minha mãe enviuvou cedo com duas crianças pequenas. Ela, que até então tinha sido dona de casa, foi obrigada a iniciar num emprego assalariado, colocando em pouco tempo seus dois filhos para contribuir com a renda familiar, com bicos de babá e jornaleiro. De temperamento um tanto difícil, ela logo rompeu com os parentes de seu falecido marido. cortando-nos - eu e meu irmão - de qualquer contato com o lado paterno da família. Depois de eu sair de casa, com 16 anos de idade, ela se casou novamente, mas o casamento acabou em pouco tempo, e minha mãe, para prosseguir sua carreira de professora, mudou de cidade. Ela, então com 6o anos, conheceu Bill, meu padrasto, com quem nunca se casou, mas com quem vive até hoje, depois cerca de 20 anos. Eu poderia ter adquirido uma irmã nessa nova união de minha mãe, já que Bill tem, de seu primeiro e único casamento, uma filha um pouco mais moça do que eu, porém nunca a encontrei, pois minha mãe se nega a recebê-la em sua casa. Em compensação, apesar de eu nunca ter morado com eles, esse senhor passou a me chamar de filha; eu o considero membro sumamente querido de minha família, devendo-lhe uma gratidão impagável pela maneira com que cuidou da minha mãe, nesses últimos anos.

Considerando os detalhes dessa minha história, dou-me conta de que minha família é qualquer coisa menos padrão, e os fatores convencionais do modelo familiar - biologia e casamento - não são nem de longe os mais importantes na definição das relações mais relevantes. Porém, mais importante: pergunto-me como, com essa trajetória, nunca me ocorreu que poderia ser proveniente de uma família "desestruturada”. A chave desse enigma, evidentemente, se remete em parte ao caráter difícil, mas disciplinado e ético de minha mãe. Não quero de forma alguma negar a agency dessa personagem. Ela, inclusive, nos ensinou muito cedo a descartar qualquer etiqueta negativa que outros pudessem atribuir a nós, por exemplo, o de "semi-órfãos". Creio que haja outro motivo para minha rejeição da conotação de "desestruturada" ligada a minha própria família. É que "desestruturada” é uma palavra usada para descrever a família dos outros. Não simplesmente outros ... ainda por cima, pobres. É como se, numa espécie de lógica post ipso facto, uma 
pessoa bem-sucedida, por definição, não poderia vir de uma família desestruturada.

Passando por esse tipo de filtro classista, conse- guimos usar, para ricos e pobres, termos diferentes, carregados de avaliações opostas, para descrever comportamentos muito semelhantes:

\section{Ricos "escolhem" sua família. \\ Maternidade assistida. \\ Produção independente. \\ Família recomposta (divórcio e recasamento).}

Pobres "submetem-se" à biologia.

Controle de natalidade.

Mãe solteira.

Família desestruturada.
É para evitar esse tipo de dualismo, para rechaçar uma perspectiva moralista que pressupõe muito mais do que devia, que a antropologia insiste no elemento (auto-) REFLEXIVO do olhar analítico.

\section{Modo de Vida: carência ou criativi- dade?}

Essa reflexividade não significa, contudo, que façamos abstração das diferenças de oportunidade, das desigualdades econômicas e sociais, entre um sujeito social e outro. As circunstâncias socioeconômicas, que são em grande parte alheias à vontade individual, são parte de qualquer modo de vida. É importante lembrar: as condições objetivas de vida levam as pessoas a olharem para o mundo de um ângulo ou de outro. Uma coisa é ter um salário fixo e um convênio de saúde, que permitem o familiar de um doente se organizar por telefone com médicos e hospitais, com hora marcada. Outra coisa é levantar às cinco da madrugada (ou passar a noite na fila) para pegar ficha de exame médico, ou esperar meses por um leito hospitalar que não sai. Essas circunstâncias obrigam as pessoas a se organizarem de forma diferente, acentuando certas prioridades e atenuando outras.

Penso mais uma vez no caso de Vanilda, que acabou por cuidar de sua mãe durante os últimos anos de vida, fazendo o milagre de sustentar uma família de seis (além dela, três de suas filhas e a mãe) com uma renda de dois salários mínimos. A "mãe velha" - como chamavam a avó, nessa família - sofria de uma forma aguda de demência senil. Não somente ficou dependente economicamente da filha, como passou a ter comportamentos agressivos e autodestrutivos, com sérios distúrbios de sono. Ninguém na casa de três cômodos dormia mais, nem Vanilda, que trabalhava das 8 da manhã às 6 da tarde, nem as filhas dela que, quando não estavam no colégio, se revezavam nos cuidados da avó. Vanilda, vendo que ela não conseguia aliviar o sofrimento da mãe, tentou repetidas vezes interná-la. Mas, como se pode imaginar, não havia vaga na rede hospitalar e era a responsabilidade da família cuidar de seus membros. Quando a "mãe velha" passou, no meio do inverno gaúcho, num frio de menos 6 graus, a arrancar a roupa e sair para a rua, completamente nua, Vanilda não teve dúvida. Resolveu deixá-la amarrada à cama enquanto o resto da família tentava dormir, mesmo sabendo que esse procedimento poderia ser visto por observadores externos como prova de extrema crueldade.

A experiência de Vanilda sublinha um último aspecto fundamental da relação entre saúde familiar e modo de vida: a demanda apresentada por cada família aos serviços públicos de saúde, isto é, ao Estado, varia muito conforme suas condições concretas de vida. Eu, por exemplo, não tive que recorrer ao Estado para cuidar da minha velha mãe, pois ela já tem aposentadoria e convênios de saúde, que são suficientes para lhe garantir condições dignas de vida, sem sobrecarregar seus familiares. Vanilda, por outro lado, aceitou o encargo de cuidar pessoalmente de sua mãe. Ao mesmo tempo, procurava desesperadamente algum apoio público para ampará-la, da mesma forma que muitos de seus vizinhos procuravam apoio de algum serviço público para ajudar no tratamento de um filho, dependente químico, ou outro membro problemático da família. Infelizmente, Vanilda, tal como a maioria de seus vizinhos, só conseguiu parcos resultados.

Ironicamente, alguns políticos chegam a sugerir que as insuficiências do serviço de saúde pública de- 
vem ser resolvidas não com mais investimento no setor, mas com políticas sociais que "fortaleçam" a família. A lógica que apresenta essas duas políticas investimento nas famílias e investimento no serviço de saúde pública -, como mutuamente excludentes, é obviamente absurda. Mas o pior é que muitas vezes a noção de que a família é o principal responsável pela saúde de seus membros vem antes de qualquer política efetiva de "fortalecimento" familiar. Desse jeito, o acento na família arrisca ficar como nada mais do que uma máxima moralista, um álibi, que desculpa a falta de empenho político num programa realmente integral de saúde.

Nessa negociação, entre Estado e família pobre, o trabalhador de saúde, especialmente os agentes de saúde familiar, fica na posição incômoda de mediador. É sensível à lógica de ambos os "mundos". Conhece as limitações do sistema de saúde e procura conter a demanda para garantir a qualidade de atendimento. Por outro lado, reconhece as limitações e necessidades das famílias. Seu desafio é caminhar nessa "corda bamba" sem resvalar inteiramente para um lado ou outro, isto é, zelar pela qualidade do sistema, sem encampar a lógica estatal que vê as famílias como culpadas por não assumir total responsabilidade por seus membros, que as rotula de "heterônimas", criticando suas demandas "exageradas" de ajuda.

Por fim, gostaria de voltar para a idéia de modo de vida, enfatizando como esse conceito evoluiu na própria história da antropologia. Não devemos esquecer que a disciplina de Antropologia surgiu no contexto colonialista do século XIX. O modo de vida dos indígenas da África, Ásia e das Américas era visto por uma primeira geração de observadores colonialistas como, na melhor das hipóteses, um fenômeno de interesse folclórico. Na maioria das vezes, no entanto, o modo de vida desses "outros" era avaliado de forma puramente negativa. Visto em termos de falta, de ausência de tudo o que os colonialistas consideravam civilizado, o modo de vida destes "outros" acabou sendo colocado como prova de primitivismo. Não é por acaso que o diálogo de então, entre colonialista e colonizado, era praticamente inexistente.
Uma nova fase de pensamento antropológico surgiu quando os antropólogos, liderados por Malinowski, no início do século XX, passaram a fazer pesquisa etnográfica de campo, isto é, aprenderam a língua dos nativos, sentaram com eles e trocaram idéias. Ao escutar as pessoas discorrerem sobre seu próprio modo de vida, suas práticas e crenças, que antes pareciam ilógicas, as tradições curiosas passaram a soar razoáveis. Foi com a pesquisa de campo que se iniciou também a fase reflexiva da antropologia, na qual, ao transformar o exótico em familiar, o pesquisador acabou por transformar o familiar em exótico (Velho, 1978). Isto é, em vez de automaticamente assumir a superioridade de seu modo de vida, ele colocou em perspectiva as crenças e práticas de sua própria civilização.

No Brasil dos dias atuais, é interessante como boa parte da literatura crítica, falando de desigualdade no país (Castell, 200o, por exemplo), lamenta a pobreza das análises sobre grupos populares, as quais ignoram qualquer positividade nas formas de sociabilidade destes grupos, que descrevem suas práticas e maneira de pensar o mundo em termos absolutamente negativos, de falta, de carência. A proposta aqui é, pelo contrário, pensar o modo de vida como fenômeno histórico, fruto de determinadas circunstâncias econômicas e políticas, e que dê prova da criatividade de indivíduos agindo em sociedade. Quero insistir que essa perspectiva, evidente nas propostas de pesquisadores, como Elsen e Althoff $(2004)^{6}$ e Dytz (2004)7, não é um acréscimo à ciência já existente. Representa algo revolucionário, uma reviravolta no senso comum, superando abordagens neocolonialistas e apontando o caminho para um espaço de verdadeiro diálogo nos programas de intervenção.

\section{Referências}

BARROS, M. L. de. Autoridade e afeto: avós, filhos e netos na família brasileira. Rio de Janeiro: Jorge Zahar, 1987. 152p.

BILAC, E. Famílias de trabalhadores: estratégias de sobrevivência. Sao Paulo: Simbolo, 1978. 157p.

6 ELSEN, I.; ALTHOFF, C. R. (Org.). Saúde da família? Multiplicar ou clarear conceitos? 2004. Trabalho apresentado no $56^{\circ}$ Congresso de Enfermagem, Gramado, 2004

7 DYTZ, J. L. O modo de vida da família e a saúde infantil. 2004. Trabalho apresentado no $56^{\circ}$ Congresso de Enfermagem, Gramado, 2004 
BOURDIEU, P. Esquisse d'une théorie de la pratique, précédé de trois études d'ethnologie kabyle. Paris: Droz, 1972. 269p.

CASTEL, R. As armadilhas da exclusão. In: CASTEL, R et al (Org.). A desigualdade e a questão social. São Paulo: EDUC, 200o. p. 15-48.

CORREA, M. Repensando a família patriarcal brasileira. In: CORREA, M. et al. (Org.). Colcha de retalhos: estudos sobre a família no Brasil. São Paulo: Brasiliense, 1982. p.15-42.

DUARTE, L. F. D. Horizontes do indivíduo e da ética no crepúsculo da família. In: RIBEIRO, I. (Org.). Família e sociedade brasileira: desafios nos processos contemporâneos. Rio de Janeiro: Fundação João XXIII, 1994. p. 23-41.

FONSECA, C. Caminhos da adoção. São Paulo: Cortez, 2002. 152p.

FONSECA, C. Família, fofoca e honra. Porto Alegre: UFRGS, 2004. 245p.

FORTES, M. Introduction. In: GOODY, J. (Org.). Development cycles in domestic groups. London: Cambridge University Press, 1958. p. 1-14.

GEERTZ, C. Os usos da diversidade. Horizontes Antropológicos, Porto Alegre, v. 10, p.13-34, 1999.
JARDIM, M. Negociando fronteiras entre o trabalho, a mendicância e o crime: uma etnografia sobre família e trabalho na Grande Porto. Porto Alegre, 1998. 51 f. Dissertação (Mestrado em Antropologia Social) - Universidade Federal do Rio Grande do Sul.

MAUSS, M. Ensaio sobre a dádiva: forma e razão da troca nas sociedades arcaicas. In: MAUSS, M. Sociologia e antropologia. São Paulo: EPU; EDUSP, 1974. p. 37-184.

PEIXOTO, C. E. Aposentadoria: retorno ao trabalho e solidariedade familiar. In: PEIXOTO, C. E. (Org.). Família e envelhecimento. Rio de Janeiro: FGV, 2004. p. 57-84.

RAPP, R. Family and class in contemporary America: notes toward an understanding of ideology. In: THORN, B; YALOM, M. (Org.). Rethinking the family: some feminist questions. Boston: Northeastern University Press, 1992. p. 49-70.

SARTI, C. A família como espelho: um estudo sobre a moral dos pobres. Campinas: FAPESP, 1996. 128p.

VELHO, G. Observando o familiar. In: NUNES, E. O. (Org.). A aventura sociológica. Rio de Janeiro: Jorge Zahar, 1978. p. 36-46.

VICTORA, C.; KNAUTH, D.; HASSEN, N. (Org.). Pesquisa qualitativa em saúde. Porto Alegre: Tomo, 2002.133p. 